\title{
Rain, Icicle, Heat and Quarantine: Reading Anthropocene: Climate Change, Contagion, Consolation by Sudeep Sen
}

\section{Reviewed by Sreetanwi Chakraborty}

Assistant Professor, Amity Institute of English Studies and Research, Amity University, Kolkata, West

Bengal, India. Mail Id: schakraborty3@kol.amity.edu | ORCID ID: 0000-0002-2936-222X

Bibliographic Information:

Name of the Book: Anthropocene: Climate Change, Contagion, Consolation

Author: Sudeep Sen

Publisher: Pippa Rann Books \& Media, UK. (2021)

Language: English

Paperback: 184 pages

ISBN-978-1-913738-38-9

Price: $£ 19.99$ | €24.99 | \$29.99 | INR.599 (hardback)

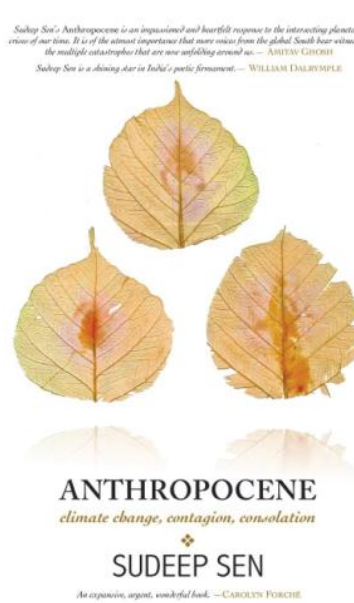

About the Author: Sudeep Sen's [www.sudeepsen.org] prize-winning books include: POSTMARKED INDIA: NEW \& SELECTED POEMS (HarperCollins), RAIN, ARIA (A. K. Ramanujan Translation Award), FRACTALS: NEW \& SELECTED POEMS | TRANSLATIONS 1980-2015 (London Magazine Editions), EROTEXT (Vintage: Penguin Random House),Kaifi Azmi: Poems I Nazms (Bloomsbury) andANTHROPOCENE: CLIMATE CHANGE, CONTAGION, CONSOLATION(Pippa Rann). He has edited influential anthologies, including: THE HARPERCOLLINS BOOK OF ENGLISH POETRY (editor), World English Poetry, and Modern English Poetry by Younger Indians (Sahitya Akademi). BLUE NUDE: EKPHRASIS \& NEW POEMS (Jorge Zalamea International Poetry Prize) and The Whispering Anklets are forthcoming. Sen's works have been translated into over 25 languages. His words have appeared in the Times Literary Supplement, Newsweek, Guardian, Observer, Independent, Telegraph, Financial Times, Herald, Poetry Review, Literary Review, Harvard Review, Hindu, Hindustan Times, Times of India, Indian Express, Outlook, India Today, and broadcast on BBC, PBS, CNN IBN, NDTV, AIR\& Doordarshan. Sen's newer work appears in New Writing 15 (Granta), Language for a New Century (Norton), Leela: An Erotic Play of Verse and Art (Collins), Indian Love Poems (Knopf/Random House/Everyman), Out of Bounds (Bloodaxe), Initiate: Oxford New Writing (Blackwell), and Name me a Word (Yale). He is the editorial director of AARK ARTS, editor of ATLAS, And currently the inaugural artist- 
in-residence at the Museo Camera. Sen is the first Asian honoured to deliver the Derek Walcott Lecture and read at the Nobel Laureate Festival. The Government of India awarded him the senior fellowship for "outstanding persons in the field of culture/literature."

The stories related to environmental history are myriad and multifaceted. The meandering maze of human destiny and its relationship to the environment weaves a magical and fascinating story every time a poet-artist like Sudeep Sen takes up his pen to write. If we go by the logic of the multiplicity of industrial ravages, we would not be surprised if the entire ecosystem and the earthly catalytic effects seem to be purposeless and doomed. But beyond that simple, calculative logic what we see through poetry, art and literature is a constant and expansive effort to narrate stories - stories of how human beings got to this present catastrophe, and how they have had an indomitable effect on the surrounding ecological system and its corresponding geological age.

A consummate poet, an artist par excellence, and an observer without any set boundaries - the internationally acclaimed poet Sudeep Sen presents an unusual and urgent artistic journey in his new book, Anthropocene: Climate Change, Contagion, Consolation. The book contains Sen's pointed and important observations in his typically original, lyrical and tightly-wrought style. Thoughts and ideas about the causality of environmental forces and their effects, is turned into the most exquisite, palpable poetry coming out of India - one that is both local and global, national and international in its outlook. The brink of human existence and the kaleidoscopic vision of human instinct and survival are painted through the changing and astute perceptions of Sen's artistic lens. As the poems and prose pieces spread their wings - they not only highlight the urgent issues of climate change and the pandemic, but simultaneously provide hope and consolation.

As the book unfurls, the poet makes us alive with conviction that "the role of the artist is not to look away" (Akira Kurosawa).As is evident in the literary texts in Anthropocene, Sen displays a very keen eye for detail, without resorting to any exaggeration - he believes in the complete avoidance of poetic excess. He renders the poems and prose pieces in a lifelike, therefore valuable and believable manner. Pondering about the infinite cosmological structure, the poet reminisces:

I marvelled at how solar and lunar gravitational pulls choreograph the seasonal orchestra how the wind's slipstreams dance, the oceans churn, and earth's tilted rotation creates the vicissitudes of tides.

('The Role of the Artist is Not to Look Away', p.17)

The apparent natural and cyclical, everyday and mundane, trajectory of earth's rotation, ocean tides and gravitational pulls - acquire a superb poetic aura and brilliance under the influence of Sen's literary techniques. He skillfully explores, locates, and understands the sublime and its enigmatic qualities. Were we mesmerized by the same poetic ebullience that Sen showed us in The Lunar Visitations (1990), Distracted Geographies (2003), Rain (2005), and many of his earlier books. 
The wretched fault lines in the dry crevices of the earth are mellowed by the soft, smooth pattering of the rains - one that reminds us of the sheer artistry that he portrayed in prose-poems like 'Icicles' and 'Photons, Graphite, Blood'. The rhetorical grandeur of the lines with their lilting tonality, incorporate profound thoughts - thoughts to rest with, and resting in thought itself.

With the swift sprinkling articulation of his emotions, the imagistic contrasts are pliable and well-calibrated. The highly alliterative intensity of the resilient and "fearless forest fires" stand in striking contrast to the "ice-caps" that "are rapidly melting - too fast to arrest the glacial slide" in 'Disembodied'. The ephemerality of human life pitted against the permanence of natural forces, act as an incubation chamber of concern for the future - and this is what the readers marvel at. Almost as a premonitory evocation, the concluding section of this poem keeps the precarious questions dangling about the future:

no GPS, no pole-star navigation, no fossil fuel to burn away just maps with empty grids and names of places that might exist.

('Disembodied', p.29)

The sheer sense of the approaching vacuity where maps will be marked by empty grids and not actual places, bring and heighten the intricate idea of revelation mixed with potential grief. This is evident in his beautifully haunting prose-poems, and a good example is 'Heavy Water':

It is the ephemeral that is painful. Water

creates all the confusion - its saltiness,

its acridity, its mineralized purity, all compete

in ways that chemical equations find hard to

support or balance.

('Heavy Water', p. 88)

The imaginative faculty susceptible to the vagaries of nature creates contested zones of what will remain of nature - a pertinent question for an impending future.

In Anthropocene, poems like 'Global Warming', 'Rising Sea Levels', 'Climate Change', 'Drought, Cloud' and 'Pollution' stand as ample testimony to the relentless force of the modern, mechanized human imprint that threatens to create an alternative mood and matrix in nature. Sen's poems take us on a journey, a journey and quest for simplicity - anon-invasive approach to release the spirit of poetic liberation, hibernating somewhere amid the "solitary cloud ... wafting" perilously in 'Drought, Cloud'. His expression is simple and lucid, yet reflective and profound:

It is bone-dry - I pray for any moisture

that might fall from the emaciate skies - 
There is a cloud, just a solitary cloud

wafting perilously -

But it is too far in the distance for any real

hope - for rain.

('Drought,Cloud', p.35)

If we scrutinize some of the most notable works on 'Anthropocene and the global environmental crisis', as explained in the area of critical writing - we find that the convergence of geological questions and human forms/settlements have raised major issues and concerns related to the way we tackle and engage with different aspects of the environment. Christophe Bonneuil, for instance, in his essay titled 'The Geological Turn: Narratives of the Anthropocene,' elucidates how nations, races, and classes have for a long time been the object of countless narratives. Eventually, the 'anthropocene' has become fundamentally associated with 'geostories', to emphasize the term used by Latour in 2013. Whether dualistic, fractured, multilayered, or boisterous narratives of the earth - these stories become testimonies of not the surface-truths, but of memories, social reverberations, and often tales that remain in the collective consciousness of the people.

In Sudeep Sen's Anthropocene: Climate Change, Contagion, Consolation, there is a poetic prism that goes beyond what can be actually seen or perceived. There is a growing consciousness that feels asphyxiated amid "the thick, heavy air", "smoke" that emanates from the burning cropfields - dense, murky and "yolky", one that provides no respite or anodyne to the exhausted soul. All these are well illustrated in most of the initial poems. It is not just a few words that the poet quotes from T S Eliot's The Waste Land or The Love Song of J Alfred Prufrock - Sen's poems become an important historical document spanning across time immemorial, time past and time present, one that coalesce into time future - similar to many of Eliot's memorable poems.

Climate change and the consequential narratives of broad expansive views of environmental changes and modifications in human settlements are neither new nor unique. As Sen points out in an interview in the environment journal/magazine The Third Pole (September 8, 2020) - "Poetry about climate change has always been out there, it's just that now it is being noticed more." He further adds, "When certain things make front-page news, then people start focusing on it."

One of the most dominant themes that we find in Sen's poetic prism is the lending and imbuing of an exquisite, extraordinary, wondrous quality to the simplest of life occurrences. Sometimes, moments of nature-human contradictions become bewildering. It is remarkable how Sen, with his deft poetic strokes, can slow-dissipate them into an illumination:

Our modest umbrellas fray,

flounder under the sun's ruthless exposure.

('Afternoon Meltdown', p.41) 
Carefully picking and choosing subjects/images, he explicates them with understated subtlety before retiring to a quaintly reflective, quiet state. And all this while playing with highly alliterative rhythms, and producing a magical orchestration of patterns, styles, alternative narratives to help us look at the broader picture of the idea of "anthropocene". Reading deeply into Sen's multifaceted poetic structures, permits us to visit and excavate layer upon layer of meanings and possibilities. Response and anticipation arise, as the poet reflects on these vital moments, nestled meditatively, sitting on the Dharamkot slopes:

watching the fading folded hills, cumulonimbus clouds veiling

Himalaya's towering snow peaks.

Another polar crest, 'the third pole' -

Like the older North-South -

slow dissolves, thaws, deliquesces.

('The Third Pole', p.42)

The overall ethereal beauty is revelatory, dazzling and illuminating at the same time. The closeness and the intricacies of "watching", and nurturing of each and every aspect of the "fading folded hills" further emphasizes the universal concept of "empty spaces" in "maps" ('Disembodied'); or "wiping out" the "white light" in the poem 'Endless Rain'.

The symphony contained in the existing ethics of nature in no way interferes with the burgeoning population that dreams and destroys. Images of wiping, melting, getting empty and evacuation are repetitive refrains in his poems. This elucidates the urgency to restore and save-save the environment when even the State and scientific advancements are failing to provide any medication or cure to the tired human soul. The world seems tumultuous, one that "fluctuates and alters with weather's polygamy" - the unrestricted unleashed, the unabashed fury of weather juxtaposed with the intensity and intimacy of its love. This is what the poet is able to present to his readers, poems that not just catapult at extreme binaries of earth-human resistance but equally channelize the reader towards an incipient realization - a discovery that the environmental crisis is itself somewhere preventing us from imagining and finding a tangible solution to the problems.

The occurrence of elemental forces - air, water, fire and earth - are also recurrent images in the modernist ideas expounded by Eliot in different segments of The Waste Land. In the words of Sen:

Rain has this special seductive appealits innocuous wet, its piercing strength, its gentle drizzle-caresses, its ability to douse and arouse.'

('Rain Charm', p.46) 
If we look at a linear projection of human history, it becomes conspicuous how the modern era can be distinguished as the midpoint of the Anthropocene. It can be defined and re-evaluated as an exceptional stage in that entire linear history. On the one hand, there is a constant, resilient form of apocalyptic anxiety that often obfuscates the rational faculty to look out for any feasible solution - and on the other hand, the changes are seen as challenges to future prediction, production and positivity. The poet's role is not one of a bystander; it is one of a visionary - one that Sen expresses through elegiac modes, metaphors, and articulation of osmosis - through scientific, historical, sociological, and political events.

The chromatic palette that Sen creates and draws for us - makes it crystal clear for us to see and experience, how he still nurtures his various interests, passions, concerns and preoccupations. Looking and longing to look beyond the known; and discovering the lingering sensation of the world of the vast and the unknown, still fascinates him - that is one of the many ways Sen's poetry conjures magic casements in the reader's heart. And all this even in the sweltering heat of summer, amid the asthmatic afternoons when his eyes are "blood-shot in acrid distress", and his breathing is infected with "dust-mite, cat hair, particulates" that draw "toxic tears".

The sheer anomalies that exist in material thought and human exigencies do not contrive to provide a shadowy poetic pillar. Instead, the conviction with which Sen paints all this - beyond disease, pestilence, and the shallow fopperies of life - shows how some day marigold and magnolia will still bloom, regardless. It is this sympathetic, soaked, free-spiritedness that allows for a harmonic rendezvous with one's soul and with the others. Playing with words and sounds like "come" and "calm", the feelings precipitate into "silence" - an ultimate recourse to "pause, reflect, love". ('Speaking in Silence', pg. 60). Or else, when he introspects

In the company of myself, I reflect.

It is time to call family, a neighbour,

a neglected friend - time to read,

rejuvenate, revive - rekindle love's labour

lost - time to savour life's little joys.

('Quarantine', p.76)

The futility, ferocity and fruition during the quarantine period thus take on a mood and moment of rekindling and savouring - a cosy, spontaneous, un-jeopardized, uninhibited urge to be loved, amid the little joys that prevail. The serrated, unbridled, rhythmic tone and momentum of an orchestra that Sen creates ushers in a new era of hope. The poems articulate moments that remain warm, temperate - the sensations of love, desire and humanity are not crushed at their core. The poems show us the light of encouragement, something that always remains in Sen's poetry and prose - using a balanced sense of tone and texture. The ease with which the rise and fall of the words' cadences appear in private spaces, create traps of ecstasy - combined with a tendency to rewrite and rekindle the lulling legacies of humankind in this powerful book, Anthropocene. 
Sen's penchant for interstices is noteworthy - parched earth, art, passion, bodily desires restive, cocooned in a fractional temperament - until the soul is liberated. All this makes the book a collector's item and an asset. Sen's poetry remains as an exquisite piece of art, as the poet confesses:

I am in pain, and I just want to cry, cry and cry - so that each searing cry can etch some fragment of a note, which has gone unnoticed, so that each measure of pain is no longer diluted for people who listen because they have to."

('Heavy Water', p.88-89)

The prolonged pain and the urgency to cry and make the world notice ideas with sensitivity something that has been long-lost, one that needs to be re-excavated to stop it from being diluted or diminished - this is Sudeep Sen's Anthropocene!

\section{Reviewer's details:}

Sreetanwi Chakraborty is an Assistant Professor in Amity Institute of English Studies and Research, Amity University Kolkata. She graduated from Presidency College Kolkata, did her Postgraduation from the University of Calcutta, and obtained her M. Phil from Rabindra Bharati University on The Sleeping Beauty Wakes Up: A Feminist Interpretation of Fairy Tales. This was published as a book in 2019, and it received the 'Rising Star' Award for non-fiction category at New Town Book Fair, Kolkata. She has been the recipient of the 'Charuchandra Ghosh Memorial Award' for securing the highest marks from Calcutta University. At present she is pursuing her Ph. D from Ranchi University (submission in February 2022). She is the Chief Editor of a bilingual biannual academic journal Litinfinite, with more than 14 indexing of international repute and archived in 57 international libraries. Apart from academic publications in reputed national and international journals, her translations and literary articles have been published in Bengali and notable English journals and magazines in India, Bangladesh, and South Africa. Her areas of interest include Indian English poetry, Indian English drama, Feminism and cultural politics, and South Asian Diasporic Studies. She has passed 5th year in Rabindra Sangeet, with distinction and 4th year in classical music from Prayag Sangeet Samiti, Allahabad. She is a trained painter in oil, acrylic, water colour and charcoal. 